\title{
Suture-less Implantation of Acoustic Transmitters in Two Salmonids
}

\author{
Nathan Huysman ${ }^{1}$, Sarah White ${ }^{1}$, Jeremy Kientz ${ }^{2}$, \\ Jill M. Voorhees ${ }^{1}$, Michael E. Barnes ${ }^{1}$
}

\author{
${ }^{1}$ South Dakota Department of Game, Fish and Parks, McNenny State Fish Hatchery, 19619 Trout Loop, Spearfish, \\ South Dakota 57783, USA \\ ${ }^{2}$ South Dakota Department of Game, Fish and Parks, 4130 Adventure Trail, Rapid City, SD 57702, USA
}

\begin{abstract}
The surgical incision required to insert acoustic transmitters into fish peritoneal cavities is typically closed with sutures, staples, or cyanoacrylate adhesive. This study evaluated a novel tag insertion technique that did not use any method of wound closure. Twenty-six adult rainbow trout (Oncorhynchus mykiss) and 26 adult brown trout (Salmo trutta) received a small, $6 \mathrm{~mm}$ abdominal incision. A dummy acoustic transmitter tag was inserted into half $(\mathrm{N}=13)$ of the fish in each species. Neither group received any wound closure; no sutures, staples, nor adhesives were used. Tag retention, wound healing, and fish survival were monitored weekly for 13 weeks postsurgery. No fish died over the course of the trial. Tag retention was $100 \%$ and $85 \%$ in the tagged rainbow trout and brown trout, respectively. The wounds in the untagged rainbow trout were all completely healed by six weeks postsurgery, while wounds of the tagged rainbow trout were completely healed at nine weeks post-surgery. Similarly, wounds in the untagged and tagged brown trout groups were completely healed by the fifth and eighth weeks respectively. This study documents the effectiveness of using a small incision with no wound closure methods during insertion of acoustic tags into rainbow trout and brown trout peritoneal cavities.
\end{abstract}

Keywords: Acoustic Transmitter, Surgery, Rainbow Trout, Oncorhynchus mykiss, Brown Trout, Salmo trutta

\section{Introduction}

Acoustic transmitters are used to track fish movements over time and space (Leber and Blankenship 2011). Transmitters are typically surgically inserted into the fish peritoneal cavity to maximize tag retention and minimize drag on the fish during swimming (Henderson et al. 1966; Wargo Rub et al. 2014). To promote healing and tag retention, transmitter incision sites have been closed with surgical staples, monofilament or silk sutures, cyanoacrylate, or a combination of these methods (Wagner et al. 2011; Wargo Rub et al. 2014). Issues with these wound closure techniques include inflammation around the incision site, poor healing, loss of sutures in the aquatic environment, risk of puncturing of organs with the suturing needle, and accumulation of organic matter on suture sites (Swanberg et al. 1999; Wagner et al. 2000; Wargo Rub et al. 2011; Schoonyan et al. 2017). Furthermore, because fish live in an un-sterile aqueous environment, suturing surgical wounds is no guarantee against pathogen entry (Wagner et al. 2011).

Post-tagging wound closure without the use of sutures, staples, or any additional measures has only been lightly evaluated. Skov et al. (2005) recommended not using sutures during surgical PIT tag implantation in small cyprinids. Baras and Jeandrain (1998) reported that eels (Anguilla anguilla) tagged without sutures had faster healing rates than those with sutures. Additionally, unsutured eels experienced no tag loss. Wargo Rub et al. (2011) reported increased survival in Chinook salmon (Oncorhynchus tshawytscha) that lost one or both sutures within seven days of surgery compared to those that retained their sutures.

Because of the lack of information on suture-less surgery for acoustic tag insertion, the objective of this study was to evaluate acoustic tag loss and wound healing in rainbow trout (Oncorhynchus mykiss) and brown trout (Salmo trutta) not receiving any method of wound closure.
Methods
This study was conducted at McNenny State Fish Hatchery (Spearfish, South Dakota, USA) using 26 adult Shasta strain rainbow trout and 26 adult Saratoga strain brown trout (Table 1). Thirteen fish from each species were randomly assigned to one of two treatments, tagged or incision-only. All fish received a small incision, with only the fish in the tagged treatment receiving a dummy acoustic

This article is published under the terms of the Creative Commons Attribution License 4.0 Author(s) retain the copyright of this article. Publication rights with Alkhaer Publications. Published at: http://www.ijsciences.com/pub/issue/2020-03/

DOI: 10.18483/ijSci.2304; Online ISSN: 2305-3925; Print ISSN: 2410-4477 
transmitter. A dummy transmitter was not inserted into the incision-only treatment group. Mean (SE) tag-to-body ratio for rainbow trout and brown trout was $0.96(0.05) \%$ and $1.09(0.05) \%$, respectively.

Fish surgeries were performed by a single trained and experienced surgeon (Jepsen et al. 2002; Mulcahy 2003; Deters et al. 2010) on June 22, 2018. Prior to surgery, fish were anesthetized using tricaine methanosulfate (MS-222; Syndel, Ferndale, Washington, USA), to stage 4 anesthesia (Hikasa et al. 1986). After anesthetization, fish were individually measured to the nearest $\mathrm{mm}$, weighed to the nearest $\mathrm{g}$, and assigned to either the treatment or control group. Adipose fins were removed from the control fish to differentiate them from any treatment fish with potential ejected tags. A small incision was made into the right ventral side of each fish approximately $1 \mathrm{~cm}$ anterior to the pelvic fins and in line with the pectoral fins using an alcohol-sterilized precision knife (X-ACTO, Elmer's Products, High Point, North Carolina, USA). The incision was approximately $6 \mathrm{~mm}$ long and just deep enough to open into the peritoneal cavity. After the incision was made, a dummy acoustic transmitter $(9 \times 24 \mathrm{~mm}, 3.6$ $\mathrm{g}$ weight in air; VEMCO, Bedford, Nova Scotia, Canada) was inserted through the incision into the peritoneal cavity of the treatment fish. The incisiononly fish did not receive a dummy transmitter. Both the treatment and incision-only fish were placed into clean water for recovery and were briefly monitored to ensure that no excessive blood loss occurred.

The fish were held in in two concrete raceways (4.7 $\mathrm{m}$ long $\times 2.4 \mathrm{~m}$ wide $\mathrm{x} 0.5 \mathrm{~m}$ deep), with each species in its own distinct raceway. Each raceway received well water at a constant temperature of $11^{\circ} \mathrm{C}$ (water hardness as $\mathrm{CaCO}_{3}=360 \mathrm{mg} / \mathrm{L}$, alkalinity as $\mathrm{CaCO}_{3}$ $=210 \mathrm{mg} / \mathrm{L}, \mathrm{pH}=7.6$, total dissolved solids $=390$ $\mathrm{mg} / \mathrm{L})$ for the 13 -week duration of the study. Fish were fed $4.5 \mathrm{~mm}$ extruded floating feed (Classic Trout, Skretting USA, Tooele, Utah, USA) once daily to satiation. At seven-day intervals, each fish was anesthetized and inspected for tag loss and wound images were recorded using a digital camera. Each image was subsequently scored on two criteria based on wound healing (closure) and inflammation (redness) at the wound site by three individuals using an adaptation of the Paukert et al. (2001) method (Table 2; Figure 1). An average of the three scores for each photograph was then used for subsequent analysis. Tag retention was calculated using the formula: retention $(\%)=100 \mathrm{x}$ (initial number of fish tagged/final number retaining tags). Tag retention was verified by dissection at the end of the study.

Data was analyzed with the SPSS (24.0) statistical analysis program (IBM, Chicago, Illinois, USA) using T-Tests. Significance was pre-determined at $p$
$<0.05$.

\section{Results}

Tag retention was $100 \%$ and $84.7 \%$ in the rainbow trout and brown trout tagged groups respectively. The tags lost in the two brown trout were both ejected from the incision site. One tag was lost during the second week after tagging while the wound was still healing. The second tag loss occurred after complete wound closure at week nine. Dissection at the end of the study revealed that most of the tags remained loose in the peritoneal cavity, while a small number were encased in body tissue.

Both trout species with tags had significantly longer healing times than the trout that only received an incision (Table 3 ). Wound closure times were nearly identical between the tagged rainbow trout and brown trout, and very similar between the incision-only fish in each species. Inflammation was significantly higher in the tagged fish in comparison to the complete absence of any visible inflammation in the incision-only trout. However, inflammation values were very low overall. All fish survived this experiment.

Both species of fish returned relatively quickly to their pre-surgery routines. Rainbow trout began feeding one day after the surgery. It took until three days post-surgery for all brown trout to resume feeding. Buoyancy problems were not observed in any fish. Neither did any fish show any visible negative effects of water infiltration into the wound site.

\section{Discussion}

The results of this study validate the use of a small, non-sutured incision for acoustic tag insertion in salmonids. The $100 \%$ survival and high tag retention rates were better than or similar to other studies where surgical incisions for tag insertion were sutured. For example, Urbaniak et al. (2016) reported $73 \%$ retention and $60 \%$ survival for sutured rainbow trout. Similarly, Bunnell and Isely (1999) observed 73 to $88 \%$ tag retention and 75 to $93 \%$ survival in sutured rainbow trout receiving transmitters. Just as with the present study, tag-to-body ratios in the Urbaniak et al. (2016) and Bunnell and Isely (1999) studies were all less than the two percent threshold recommended by Jepsen et al. (2005). Higher tag-tobody ratios may negatively impact tag retention (Rechisky et al. 2009: Smircrich and Kelly 2014)., although other studies have reported good tag retention results at ratios greater than two percent (Brown et al. 1999; Chittenden et al. 2009; Rechisky and Welch 2009; Smircrich and Kelly 2014; Klinard et al. 2018).

The wound healing times of six-to-seven weeks for 
tagged fish in this study are typical for trout undergoing surgery at the hatchery. Prior unpublished observations indicated wound closure times from four-to-six weeks in untagged and tagged rainbow trout receiving sutures. In walleye (Sander vitreus) partial wound closure occurred at nine weeks postsurgery, with complete closure after 21 weeks (Schoonyan et al. 2017). And in channel catfish (Ictalurus punctatus) healing of a relatively lengthy incision with no wound closure took approximately four weeks (Carmichael 1991). The extremely small incision used in the current study likely facilitated the rapid healing properties of the trout integument (Noga 2000; Fotenot and Neiffer 2004).

In comparison to suture-based wound closure techniques, there was little to no inflammation observed in this study. This is likely due to the absence of sutures. Suturing materials are known to induce inflammatory responses in fish (Mulcahy 2003; Wagner et al. 2011). In addition, the small puncture method used in this current study likely caused less trauma around the surgical site compared to a longer incision. The relative lack of wound inflammation in this study may also be due to the relatively low water temperature used. Higher temperatures have been related to increased wound inflammation in salmonids and other fish species (Knights and Lasee 1996; Bunnell and Isely 1999; Deters et al. 2010).

The ventral surface of the fish is the most accepted location for surgical procedures (Mulcahy 2003; Wargo Rub et al. 2014) with most incisions occurring just off the linea alba (Wagner et al. 2011). The lateral surgical site in this study was chosen in an attempt to prevent tag loss through the un-sutured hole left behind following insertion. Lateral incisions may be problematic however and have been associated with increased mortality in brown trout (Clapp et al. 1990), and an increased risk of ovarian puncture (Schramm and Black 1984). The high survival, lack of irritation, rapid wound healing, and high tag retention in the current study indicates the acceptability of using a lateral incision with the novel, non-sutured, surgical technique.

The non-suture method of tag insertion described in this study likely has additional benefits beyond the excellent tag retention, rapid wound closure, and lack of inflammation. It should be considerably faster to perform than surgical methods using sutures or more extensive wound closure techniques, although this needs to be verified in future studies. Faster surgery means less time for the fish to be under anesthesia and less time out-of-the-water. In addition, not having to tie precise suturing knots decreases the risk of organ puncture, negates the need for a skilled surgeon, and eliminates the skilled surgeon-to-skilled surgeon variation in wound healing (Deters et al. 2010).

In conclusion, the surgical technique to insert an acoustic transmitter described in this study using small incision without any wound closure appears to be very safe and extremely effective, at least with the fish and tag sizes used. Additional research is obviously needed to directly compare this technique with the traditional suturing method, as well as with other sizes of tags and other species and sizes of fish.

\section{Acknowledgements:}

We thank Eric Krebs and Allisa Muggli for their assistance with this experiment.

\section{References}

1. Baras, E., and D. Jeandrain. 1998. Evaluation of surgery procedures for tagging eel Anguilla Anguilla (L.) with biotelemetry transmitters. Hyrdobiologia 371/372:107-111. https://doi.org/10.1007/978-94-011-5090-3_13

2. Brown, R.S., S.J. Cooke, W.G. Anderson, and R.S McKinley. 1999. Evidence to challenge the " $2 \%$ " rule for biotelemetry. North American Journal of Fisheries Management 19:867-871. https://doi.org/10.1577/15488675(1999)019<0867:etctrf > 2.0.co;2

3. Bunnell, D.B., and J.J. Isely. 1999. Influence of temperature on mortality and retention of simulated transmitters in rainbow trout. North American Journal of Fisheries Management 19:152-154. https://doi.org/10.1577/15488675(1999)019<0152:iotoma>2.0.co;2

4. Carmichael, G.J. 1991. Recovery of channel catfish from abdominal surgery. The Progressive Fish-Culturist 53:193195. 8640(1991)053<0193:roccfa>2.3.co;2 https://doi.org/10.1577/1548

5. Chittenden, C.M., K.G. Butterworth, K.F. Cubitt, M.C. Jacobs, A. Ladouceur, D.W. Welch, and R.S. McKinley. 2009. Maximum tag to body size ratios for an endangered coho salmon (O. kisutch) stock based on physiology and performance. Environmental Biology of Fishes 84:129-140. https://doi.org/10.1007/s10641-008-9396-9

6. Clapp, D.F., R.D. Clark Jr., and J.S. Diana. 1990. Range, activity, and habitat of large, free-ranging brown trout in a Michigan stream. Transactions of the American Fisheries Society 119:1022-1034. https://doi.org/10.1577/15488659(1990)119<1022:raahol>2.3.co;2

7. Deters, K.A., R.S. Brown, K.M. Carter, J.W. Boyd, M.B. Eppard, and A.G. Seaburg. 2010. Performance assessment of suture type, water temperature, and surgeon skill in juvenile chinook salmon surgically implanted with acoustic transmitters. Transactions of the American Fisheries Society 139:888-899. https://doi.org/10.1577/t09-043.1

8. Fontenot, D.K., and D.L. Neiffer. 2004. Wound management in teleost fish: biology of the healing process, evaluation, and treatment. The Veterinary Clinics Exotic Animal Practice 7:57-86. https://doi.org/10.1016/j.cvex.2003.08.007

9. Henderson, H., A.D. Hasler, and G.G. Chipman. 1966. An ultrasonic transmitter for use in the studies of movement of fishes. Transactions in the American Fisheries Society 95:350-356. https://doi.org/10.1577/15488659(1966)95[350:autfui]2.0.co;2

10. Hikasa, Y., K. Takase, T. Ogasawara, and S. Ogasawara. 1986. Anesthesia and recovery with tricaine methanesulfonate, eugenol and thiopental sodium in the carp, Cyprinus carpio. Japanese Journal of Veterinary Science 48:431-351. https://doi.org/10.1292/jvms1939.48.341

11. Jepsen, N., A. Koed, E.B. Thorstad, and E. Baras. 2002 Surgical implantation of telemetry transmitters in fish: how much have we learned. Hydrobiologia 483:239-248. https://doi.org/10.1007/978-94-017-0771-8_28 
12. Jepsen, N., C. Schreck, S. Clements, and E.B. Thorstad. 2005. A brief discussion of the $2 \%$ tag/bodymass rule of thumb. In: Spedicato, M.T., G. Lembo, and G. Marmulla (eds) Aquatic Telemetry: Advances and Applications. FAO/COISPA Rome, Italy (225-260).

13. Klinard, N.V., E.A. Halfyard, A.T. Fisk, T.J. Stewart, and T.B. Johnson. 2018. Effects of surgically implanted acoustic tags on body condition, growth, and survival in a small, laterally compressed forage fish. Transactions of the American Fisheries Society 147:749-757. https://doi.org/10.1002/tafs.10064

14. Knights, B.C., and B.A. Lasse. 1996. Effects of implanted transmitters on adult bluegills at two temperatures. Transactions of the American Fisheries Society 125:440-449. https://doi.org/10.1577/1548-

8659(1996)125<0440:eoitoa>2.3.co;2

15. Leber, K.M., and H. L. Blankenship. 2011. How advances in tagging technology improved progress in a new science: marine stock enhancement. American Fisheries Society Symposium 76.

16. Mulcahy, D.M. 2003. Surgical implantation of transmitters into fish. Institute for Laboratory Animal Research 44:295306. https://doi.org/10.1093/ilar.44.4.295

17. Noga, E.J. editor. 2000. Pharmacopoeia. In: Fish disease: diagnosis and treatment. Ames, Iowa, USA. Iowa State Press (271-299).

18. Paukert, C.P., P.J. Chavala, B.L. Heikes, and M.L. Brown. 2001. Effects of implanted transmitter size and surgery on survival, growth, and wound healing of bluegill. Transactions of the American Fisheries Society 125:707-714. https://doi.org/10.1577/15488659(2001)130<0975:eoitsa $>2.0 . c 0 ; 2$

19. Rechisky, E.L., and D.W. Welch. 2009. Surgical implantation of acoustic tags: influence of tag loss and taginduced mortality on free ranging and hatchery-held spring Chinook (O. tschawytscha) smolts. In: PNAMP Special Publication: Tagging, telemetry and marking measures for monitoring fish populations - a compendium of new and recent science for use in informing technique and decision modalities. Pacific Northwest Aquatic Monitoring Partnership (1-96).

20. Schoonyan, A., R.T. Kraus, M.D. Faust, C.S. Vandergoot, S.J. Cooke, H.A. Cook, T.A. Hayden, and C.C. Krueger. 2017. Estimating incision healing rate for surgically implanted acoustic transmitters from recaptured fish. Animal
Biotelemetry 5:15. https://doi.org/10.1186/s40317-017-01302

21. Schramm, H.L. Jr., and D.J. Black. 1984. Anaesthesia and surgical procedures for implanting radio transmitters into grass carp. Progressive Fish Culturist 46:185-190. https://doi.org/10.1577/1548 8640(1984)46<185:aaspfi>2.0.co;2

22. Skov, C., J. Brodersen, C. Brönmark, L.A. Hansson, P. Hertonsson, and P.A. Nilsson. 2005. Evaluation of PIT tagging in cyprinids. Journal of Fish Biology 67:1195-1201. https://doi.org/10.1111/j.1095-8649.2005.00814.x

23. Smircich, M.G., and J.T. Kelly. 2014. Extending the $2 \%$ rule: the effects of heavy internal tags on stress physiology, swimming performance, and growth in brook trout. Animal Biotelemetry 2:16. https://doi.org/10.1186/2050-3385-2-16

24. Swanberg, T.R., D.A. Schmetterling, and D.H. McEvoy. 1999. Comparison of surgical staples and silk sutures for closing incisions in rainbow trout. North American Journal of Fisheries Management 19:215-218 https://doi.org/10.1577/1548-

8675(1999)019<0215:cossas > 2.0.co;2

25. Urbaniak, T.J., M.E. Barnes, and J.L. Davis. 2016. Acoustic transmitters impact rainbow trout growth in a competitive environment. The Open Fish Science Journal 9:37-44. https://doi.org/10.2174/1874401x01609010037

26. Wagner, G.N., E.D. Stevens, and P. Byrne. 2000. Effects of suture pattern on surgical wound healing in rainbow trout. Transactions of the American Fisheries Society 129:11961205. 8659(2000)129<1196: eostap >2.0.co;2 https://doi.org/10.1577/1548

27. Wagner, G.N., S.J. Cooke, R.S. Brown, and K.A. Deters 2011. Surgical implantation techniques for electronic tags in fish. Reviews in Fish Biology and Fisheries 21:71-81. https://doi.org/10.1007/s11160-010-9191-5

28. Wargo Rub, A.M., B.P. Sandlord, L.G. Gilbreath, M.S. Meyers, M.E. Peterson, L.L. Charlton, S.G. Smith, and G.M Matthews. 2012. Comparative performance of acoustic tagged and passive integrated transponder tagged juvenile Chinook salmon in the Columbia and Snake Rivers, 2008 Seattle: Fish Ecology Division. Northwest Fisheries Science Center. National Marine Fisheries Service.

29. Wargo Rub, A.M., N. Jepsen, T.L. Liedtke, M.L. Moser, and E.P. Scott Weber III. 2014. Surgical insertion of transmitters in fisheries research. American Journal of Veterinary Research 75:4. https://doi.org/10.2460/ajvr.75.4.402

Table 1. Mean (SE) initial lengths and weights for rainbow trout and brown trout subjected to either dummy transmitter implantation (treatment) or just a surgical incision (control) $(\mathrm{N}=13)$.

\begin{tabular}{rlrr}
\hline & \multicolumn{1}{c}{ Group } & Length $(\mathrm{mm})$ & Weight $(\mathrm{g})$ \\
\hline \multirow{3}{*}{ Sainbocies } & & & \\
& & $344(6)$ & $539(31)$ \\
& Incision-only & $319(5)$ & $393(25)$ \\
Tagged & & $289(7)$ & $357(34)$ \\
\cline { 2 - 4 } & Incision-only & $291(4)$ & $337(17)$ \\
\hline
\end{tabular}

Table 2. Scoring criteria for wound gape severity and wound redness severity used to determine surgical wound healing for rainbow trout following dummy acoustic transmitter insertion surgery and utilizing three different wound closure methods.

\begin{tabular}{cll}
\hline Score & Wound Healing & Wound Redness \\
\hline 0 & Complete closure & No redness present \\
1 & Closure of $<50 \%$ & Redness localized to incision/suture site \\
2 & No closure & Redness extended beyond incision/suture site \\
\hline
\end{tabular}


Suture-less Implantation of Acoustic Transmitters in Two Salmonids

Table 3. Mean (SE) weeks required for $50 \%$ and complete wound closure, and the duration of visible inflammation in rainbow trout and brown trout subjected to a small surgical incision, with or without the insertion of a dummy acoustic transmitter tag. Means in a row followed by a different letter are significantly different $(\mathrm{P}<0.05 ; \mathrm{N}=13)$.

\begin{tabular}{lcc}
\hline & Incision-Only & Tagged \\
\hline Rainbow trout & & \\
& & \\
Weeks to 50\% wound closure & $1.9(1.1) \mathrm{a}$ & $4.9(0.6) \mathrm{b}$ \\
Weeks to complete wound closure & $5.0(0.2) \mathrm{a}$ & $6.3(1.3) \mathrm{b}$ \\
Weeks of inflammation & $0.0(0.0) \mathrm{a}$ & $0.7(1.2) \mathrm{b}$ \\
\hline Brown trout & & \\
Weeks to 50\% wound closure & & $4.9(0.8) \mathrm{b}$ \\
Weeks to complete wound closure & $1.6(1.0) \mathrm{a}$ & $6.3(1.0) \mathrm{b}$ \\
Weeks of inflammation & $4.1(0.6) \mathrm{a}$ & $0.2(0.4) \mathrm{b}$ \\
\hline
\end{tabular}

Figure 1. Photographs of rainbow and brown trout representing various stages of healing. The number on each photograph designates the wound closure or redness/inflammation score.

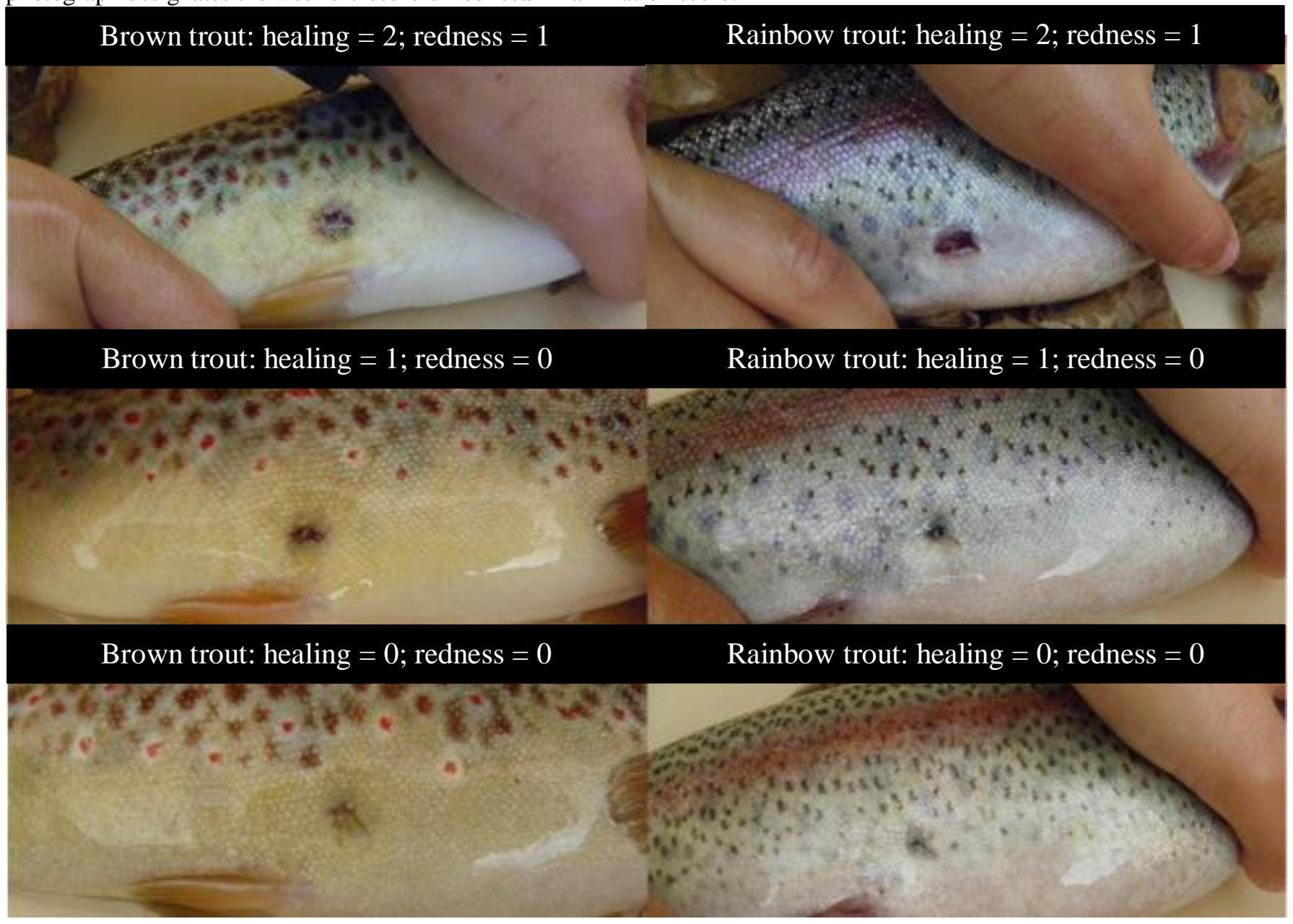

